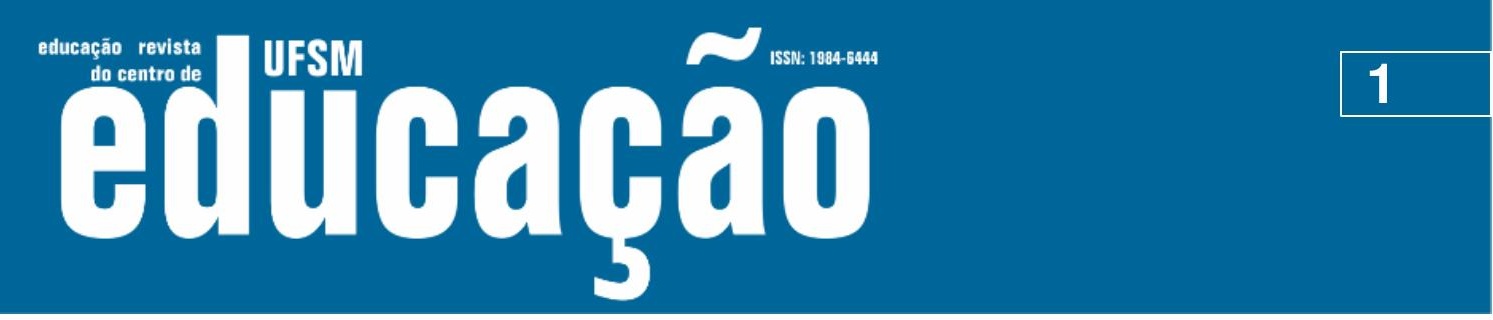

ISSN: 1984-6444 | http://dx.doi.org/10.5902/1984644434731

\title{
A reforma do Ensino Médio e a produção de desigualdades na educação escolar
}

The reform of Middle School and the production of inequalities in school education

*Paulo Romualdo Hernandes
Professor doutor da Universidade Federal de Alfenas, Alfenas, Minas Gerais, Brasil.
paulorh_mancini@hotmail.com - http://orcid.org/0000-0001-7360-4460

Recebido em 12 de setembro de 2018

Aprovado em 02 de junho de 2019

Publicado em 15 de julho de 2019

\section{RESUMO}

Examina-se, neste artigo, a reforma do Ensino Médio, editada pela lei 13.415 (BRASIL, 2017). Dar-se-á atenção especial ao estabelecimento de um teto máximo de 1.800 horas para cumprimento do ensino dos conteúdos escolares, bem como à nova composição do currículo e sua flexibilização. O estudo tem como fundamento teórico-metodológico a teoria histórico-crítica, em sua concepção dialética de pesquisa e em sua posição sobre a razão de ser da escola. Constatou-se que a flexibilização do currículo, a partir de um discurso de modernização da estrutura curricular, trará diversas dificuldades para as escolas, principalmente aquelas mantidas pelo Poder Público, cumprirem com sua função social - a transmissão e assimilação de saberes elaborados, científicos - promovendo acentuadas desigualdades no Ensino Médio.

Palavras-chave: Ensino Médio; Lei 13.415; Teoria Histórico-crítica.

\section{ABSTRACT}

This article examines the reform of secondary education, edited by law 13,415(BRASIL, 2017). Particular attention will be paid to the establishment of a ceiling of 1,800 hours for the fulfillment of the teaching of school contents, as well as to the new composition of the curriculum and its flexibility. The study has as theoreticalmethodological foundation the historical-critical theory, in its dialectical conception of research and in its position on the reason of being of the school. It was found that this flexibilization of the curriculum, from a discourse of modernization of the curricular structure, will bring several difficulties for schools, especially those maintained by the 


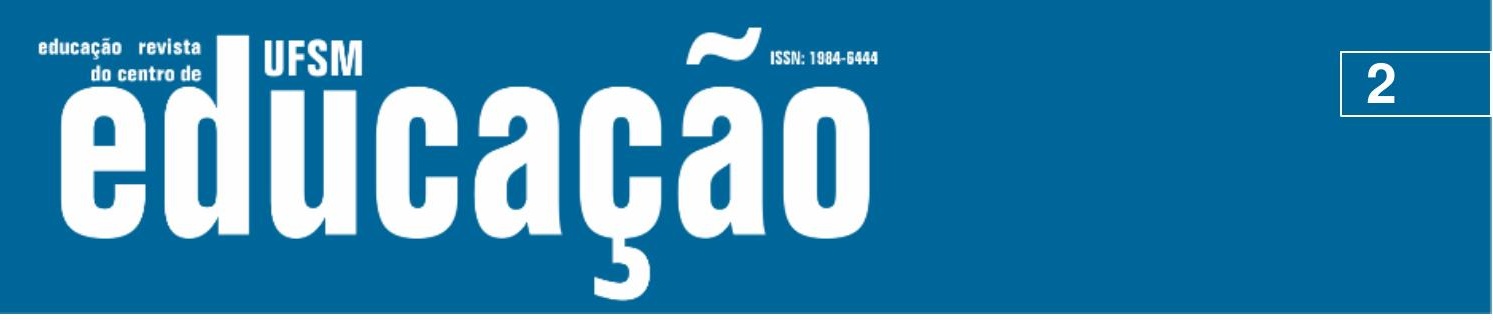

ISSN: 1984-6444 | http://dx.doi.org/10.5902/1984644434731

Public Power, to fulfill their social function - the transmission and assimilation of developed knowledge - promoting high inequalities in secondary education.

Keywords: High School; Law 13.415; Historical-critical Theory.

\section{Introdução}

A lei 13.415 (BRASIL, 2017), que trata da reforma do Ensino Médio, entre outras providências, determinou a progressiva ampliação da carga horária dessa etapa da educação básica até tornar-se ensino de tempo integral. Essa ampliação veio acompanhada pelo estabelecimento da Base Nacional Comum Curricular $(B N C C)^{i}$ como documento que "definirá direitos e objetivos de aprendizagem do Ensino Médio". Entretanto, impôs limite ao cumprimento da BNCC, que não deve ser superior a 1.800 horas. Neste limite, flexibilizou aos sistemas de ensino a escolha de quantas e quais disciplinas ofertar aos estudantes, excetuando-se as que são obrigatórias: português, matemática e inglês. Apresenta, ainda, uma inovação para compor o currículo, também em forma de flexibilização, na criação de itinerários formativos, com cinco arranjos curriculares, a serem organizados pelos sistemas de ensino, segundo relevância que atribuam e possibilidades que tenham em ofertá-los. Assim, parte da carga horária deve ser destinada à BNCC, até um máximo de 1.800 horas, e a outra parte para itinerários formativos (BRASIL, 2017).

O principal interesse deste artigo é analisar a reforma do Ensino Médio, que foi imposta à sociedade brasileira por meio de uma lei que teve início com uma medida provisória, que, levando-se em conta a "amplitude da reforma e da ausência de uma discussão democrática, [...] não poderia gerar outra coisa senão a revolta de diversos segmentos sociais ligados à educação" (SILVA; BOUTIN, 2018, p. 523). A reforma do Ensino Médio foi iniciada pela edição da medida provisória 746, em setembro de 2016. Conforme a Constituição Federal (BRASIL, 1988), edita-se uma medida provisória quando a matéria é de relevância e urgência. Segundo Ivo Dantas, medida provisória no Brasil se tornou forma de o Poder Executivo federal legislar. Atende, na verdade, "manifestação da vontade imperial do Poder Executivo" (DANTAS, 2008, p. 15). Em fevereiro de 2017, a medida provisória 746 foi rapidamente convertida na lei 13.415 , sem contar com a devida e necessária participação da comunidade educativa em sua 


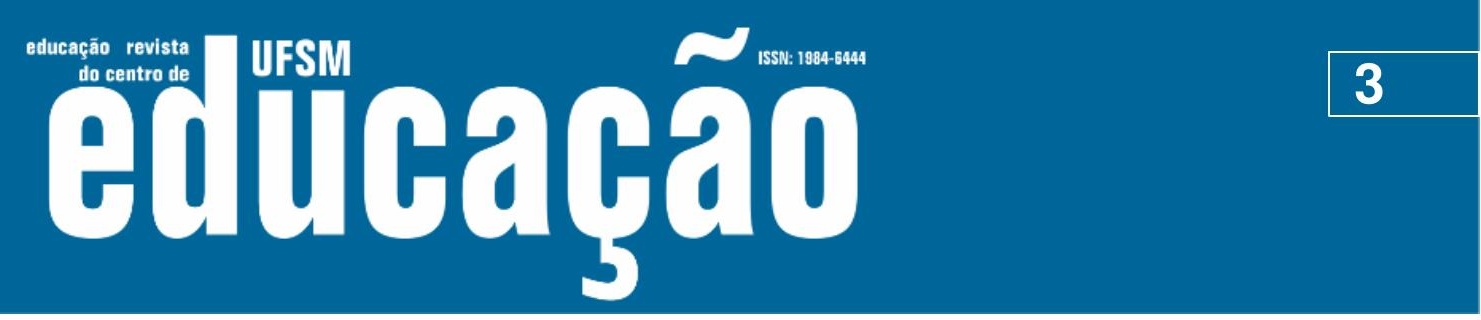

ISSN: 1984-6444 | http://dx.doi.org/10.5902/1984644434731

elaboração. Legitimada pela forma jurídica, a reforma expressa "marcas de uma determinada política e lógica de produção, de um Estado de direito da sociedade dividida em classes e representante de uma classe hegemônica" (TORRIGLIA; ORTIGARA, 2014, p. 197). Na realidade e não no discurso retórico, o que está em jogo não é reformar, modernizar ou adequar a etapa final da educação básica, mas a disputa por hegemonia.

Investiga-se o que o Estado pretende alterar na realidade concreta do Ensino Médio que se tem constituído na história da educação brasileira de "mais difícil enfrentamento, em termos de sua concepção, estrutura e formas de organização, em decorrência de sua própria natureza de mediação entre a educação fundamental e a formação profissional stricto sensu" (KUENZER, 1997, p. 77). Parte-se do pressuposto de que a lei 13.415 impõe ao Ensino Médio, na realidade, uma contrarreforma, assim designada por Elisa B. Ferreira (2017), por ser um retrocesso a reformas ditas neoliberais propostas no governo de Fernando Henrique Cardoso. Como política pública, forma e conteúdo jurídico e ideológico, a lei 13.415 se expressa no interior de uma totalidade social e defende os interesses da classe empresarial. Situa-se no movimento dialético real, em suas determinações concretas, e "carrega normas e orientações para efetivar comportamentos sociais necessários para a sustentação do modo de produção - na atualidade, o capitalismo" (TORRIGLIA; ORTIGARA, 2014, p. 189). A contrarreforma mascara - com discurso frágil de que atende o interesse de todos, sobretudo da classe trabalhadora - que, na realidade concreta, pretende fazer ajustes necessários à lógica do capital.

Este estudo se inscreve em pesquisas mais amplas que têm investigado políticas públicas que afetam a função social da escola, tendo como fundamento a concepção de educação escolar da teoria histórico-crítica: "a escola diz respeito ao conhecimento elaborado e não ao conhecimento espontâneo; ao saber sistematizado e não ao saber fragmentado; à cultura erudita e não à cultura popular" (SAVIANI, 2000, p. 19). Conhecimento elaborado, saber sistematizado, cultura erudita que não são verbalistas e abstratos, mas que possibilitam a inteligibilidade do real, a aquisição de signos culturais, a formulação de conceitos e a transformação da realidade concreta (MARTINS, 2013). A investigação, portanto, não se limita à análise da lei 13.415, mas 


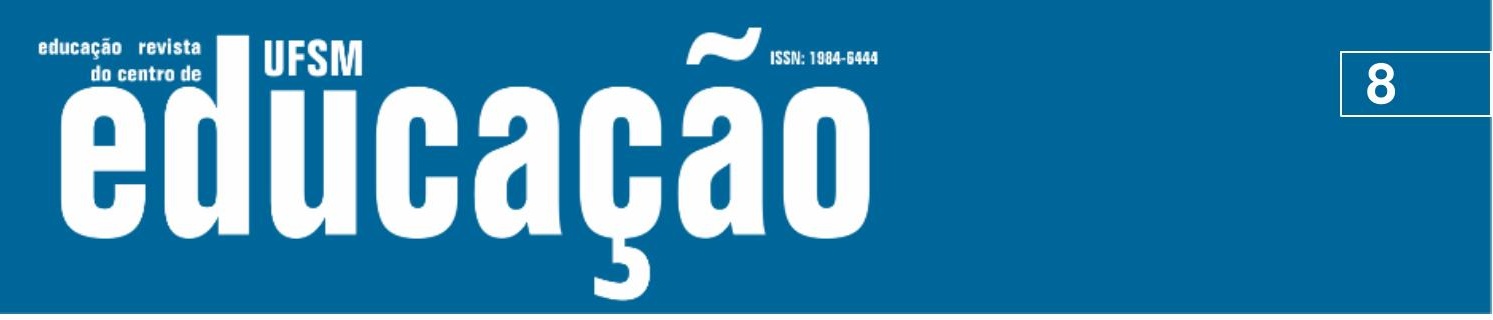

ISSN: 1984-6444 | http://dx.doi.org/10.5902/1984644434731

alunos e destes com o professor, por meio de fóruns, e-mails e até webconferências, ela não estabelece suficiente interação professor-aluno, essencial para o processo de ensino e aprendizagem dos conteúdos complexos da educação escolar (KUENZER, 2017; HERNANDES, 2017). De qualquer modo, não parece ser a educação a distância interativa que os sistemas de ensino ofertariam para seus estudantes. Afinal, esta demandaria recursos mais elevados que os pacotes de informações produzidos para o consumo dos estudantes (HERNANDES, 2017).

\section{Arranjo curricular, formação técnica e profissional e o retrocesso à dualidade do Ensino Médio}

O arranjo curricular $\mathrm{V}$ - formação técnica e profissional, proposto pela lei 13.415, é um retrocesso à lei 2.208/97 (KUENZER, 2017), que impunha à sociedade brasileira a dualidade entre ensino profissional, de um lado, e geral, de outro. Tem como objetivo promover rápido treinamento dos estudantes da classe trabalhadora em atividades ocupacionais flexíveis, a fim de atender o mercado de trabalho com ocupações também flexíveis. Para fazer isso sem demandar recursos financeiros e, ainda, atender os interesses dos empresários, a lei propõe saídas que comprovam que atende, realmente, a lógica do capital e não os interesses dos estudantes de nível médio. Estabelece o parágrafo $6^{\circ}$ do artigo $4^{\circ}$, da lei 13.415 :

\footnotetext{
A critério dos sistemas de ensino, a oferta de formação com ênfase técnica e profissional considerará: I - a inclusão de vivências práticas de trabalho no setor produtivo ou em ambientes de simulação, estabelecendo parcerias e fazendo uso, quando aplicável, de instrumentos estabelecidos pela legislação sobre aprendizagem profissional; II - a possibilidade de concessão de certificados intermediários de qualificação para o trabalho, quando a formação for estruturada e organizada em etapas com terminalidade (BRASIL, 2017, p. 16).
}

Sai de cena a escola como locus de formação do aluno, entram o setor produtivo ou os ambientes de simulação. Não mais os conhecimentos sistematizados serão ensinados, mas as vivências práticas de trabalho. Essa formação aligeirada pode render certificado de qualificação em alguma profissão e "liberar" o aluno de completar o Ensino Médio antes mesmo que ele conclua o curso. Esse treinamento 


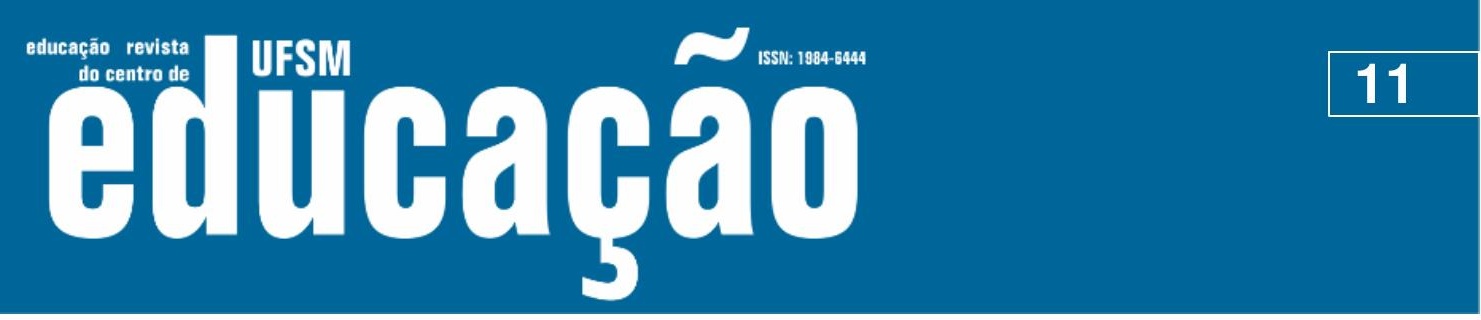

ISSN: 1984-6444 | http://dx.doi.org/10.5902/1984644434731

Ao inserir entre os itinerários formativos o arranjo curricular de formação técnica e profissional, o Poder Público se desobriga e se desonera do Ensino Médio público, como também da educação superior pública para acesso às classes populares, e ainda "libera" para as corporações um exército de reserva de jovens e flexíveis trabalhadores de baixa qualificação.

A Reforma do Ensino Médio procura adequar essa modalidade de ensino para os estudantes das classes populares ao modo de produção capitalista dos tempos atuais, que exige um trabalhador flexível que se adapte às forças do trabalho, também flexíveis (KUENZER, 2017). Segundo Kuenzer, a formação técnica e profissional:

é disponibilizada d forma diferenciada por origem de classe, de modo a levar
os que vivem do trabalho a exercer, e aceitar, de forma natural, as múltiplas
tarefas do mercado flexibilizado. Ser multitarefa, neste caso, implica exercer
trabalhos disponibilizados pelo mercado, para os quais seja suficiente um
rápido treinamento, a partir de algum aporte de educação geral, seja no nível
básico, técnico ou superior (KUENZER, 2017, p. 341).

A educação escolar não pode secundarizar a formação do aluno trabalhador no que é específico de seu propósito de ensino por um currículo de treinamento em alguma técnica ou profissão. Do ponto de vista da evolução do pensamento, o treinamento utilitário e pragmático de uma técnica ou profissão não possibilita a estimulação do pensamento abstrato; não há desenvolvimento da formação das funções psíquicas superiores (MARTINS, 2013), expandidas por meio "das capacidades intelectuais, das operações lógicas do raciocínio, dos sentimentos éticos e estéticos, dos conhecimentos clássicos, enfim, de tudo que garanta ao indivíduo a qualidade de ser humano e que dependem em alto grau das dimensões qualitativas da formação escolar" (MARTINS, 2013, p. 375). Os estudantes das classes populares, recebendo doses homeopáticas de conhecimentos científicos, complexos, sistematizados, terão dificuldades no acesso e na permanência no Ensino Superior.

\section{Profissionais de notório saber na escola e a negligência com a profissão docente}

O artigo 6ำ da lei 13.415, que altera o inciso IV do artigo 61 da LDBEN, traz mais exemplos de flexibilidade que, de tanto flexibilizar-se, podem descaracterizar a 


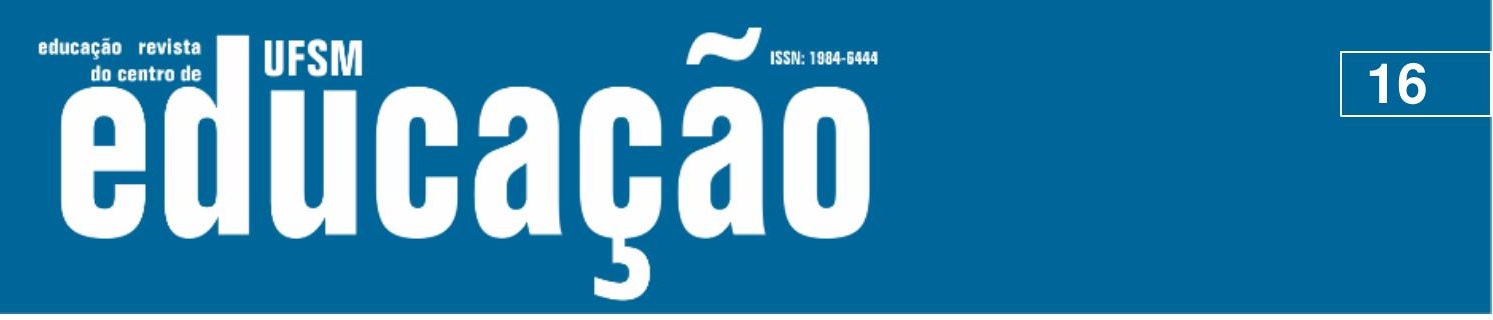

ISSN: 1984-6444 | http://dx.doi.org/10.5902/1984644434731

trabalho, como também o pleno desenvolvimento das funções psíquicas superiores essenciais para a compreensão e elaboração de conceitos complexos. O que está em jogo na reforma do Ensino Médio, imposta por medida provisória, rapidamente transformada em lei, é o "controle do processo formativo da juventude (objetivos, métodos e conteúdos), fundamental para o controle ideológico da escola e seu alinhamento à lógica das necessidades do aparato produtivo" (FREITAS, 2016, p. 140).

A superação desse controle formativo que segue na direção dos interesses da classe dominante, dos capitalistas, e coloque a escola, o Ensino Médio, nos rumos dos interesses das classes populares, deve seguir na contracorrente da contrarreforma. Deve conduzir-se na contramão da desapropriação dos saberes sistematizados que a reforma do Ensino Médio quer impor à classe trabalhadora, para reapropriá-la desses saberes, possibilitando a essa classe a aquisição e elaboração de conceitos complexos, das ciências, da filosofia, da arte. A apropriação desses conhecimentos elaborados é condição fundamental para a emancipação dos sujeitos individuais e coletivos das classes populares.

\section{Referências}

AMARAL, Nelson Cardoso. Com a PEC 241/55 (EC95) haverá prioridade para cumprir as metas do PNE (2014-2024)? Revista Brasileira de Educação, v. 22, n. 71, e227146, 2017. Disponível em: http://dx.doi.org/10.1590/s1413-24782017227145. Acesso em: fev de 2018.

ANPED. Nota da ANPEd sobre a entrega da terceira versão da Base Nacional Comum Curricular (BNCC) ao Conselho Nacional de Educação (CNE) em 10/04/2017. Disponível em: http://www.anped.org.br/news/nota-da-anped-sobre-entrega-daterceira-versao-da-base-nacional-comum-curricular-bncc-ao. Acesso em: maio 2017.

BRASIL. Constituição da República Federativa do Brasil. São Paulo: Imprensa Oficial do Estado de São Paulo, 1988.

BRASIL. Lei no 9.394, de 20 de dezembro de 1996. Estabelece as diretrizes e bases da educação nacional. Diário Oficial da União, 23/12/1996. Disponível em: http://www.planalto.gov.br/ccivil_03/leis/L9394.htm.

BRASIL. Lei nำ13.415, de 16 de fevereiro de 2017, conversão da medida provisória 746, de 2016. Diário Oficial da União, 17/02/2017. Disponível em: 


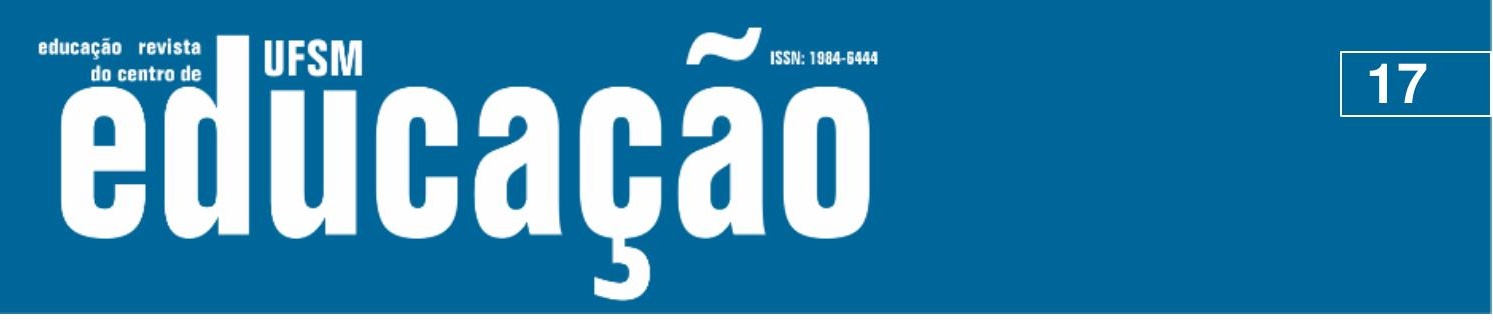

ISSN: 1984-6444 | http://dx.doi.org/10.5902/1984644434731

http://www2.camara.leg.br/legin/fed/lei/2017/lei-13415-16-fevereiro-2017-784336publicacaooriginal-152003-pl.html.

CORBUCCI, Paulo. Roberto. Financiamento e democratização do acesso à educação superior no Brasil: da deserção do Estado ao projeto de reforma. Educação \& Sociedade, Campinas, v. 25, n. 88, p. 677-701, 2004. Disponível em: http://doi.org/10.1590/S0101-73302004000300003.

CUNHA, Luiz Antônio. As agências financeiras internacionais e a Reforma Brasileira do Ensino Técnico: a crítica da crítica. In ZIBAS, Dagmar; AGUIAR, Marcia Ângela da Silva; BUENO, Maria Sylvia Simões Bueno. Ensino Médio e a Reforma da Educação Básica. Brasília: Plano, 2002.

DANTAS, Ivo. Medida provisória: Uma manifestação de vontade imperial do Poder Executivo à luz de uma análise crítica da EC no 32. In VIEIRA, José. Ribas. (org.). 20 anos da Constituição cidadã de 1988: efetivação ou impasse institucional? Rio de Janeiro: Forense, 2008.

DUARTE, Newton. Os conteúdos escolares e a ressureição dos mortos. Contribuição à teoria histórico-crítica do currículo. Campinas, SP: Autores Associados, 2016.

FERREIRA JR., Amarílio; BITTAR, Marisa. A educação na perspectiva marxista: uma abordagem baseada em Marx e Gramsci. Interface - Comunic., Saúde, Educ., v.12, n.26, p.635-46, jul./set. 2008. Disponível em: http://www.scielo.br/pdf/icse/v12n26/a14.pdf. Acesso em 05/09/2018.

FERREIRA, Elisa. Bartolozzi. A contrarreforma do Ensino Médio no contexto da nova ordem e progresso. Educação e Sociedade, Campinas, v. 38, n. 139, p. 293-308, 2017. Disponível em: http://dx/doi.org/101590/ES0101-73302017176594. Acesso em: $12 / 02 / 2018$.

FERRETI, Celso João; SILVA, Monica. Ribeiro da. Reforma do Ensino Médio no contexto da Medida Provisória no 746/2016: Estado, currículo e disputas por hegemonia. Educação e Sociedade, Campinas, v. 38, n. 139, p. 385-404, 2017. Disponível em: http://dx/doi.org/101590/ES0101-73302017176607. Acesso em: 09/02/2018.

FREITAS, Luiz Carlos de. Três teses sobre as reformas empresariais da educação: perdendo a ingenuidade. Cad. Cedes, Campinas, v. 38, n. 99, p. 137-153, 2016. Disponível em: http://dx.doi.org/10.1599/CC0101-326220160502.Acesso em $12 / 03 / 2018$

FREITAS, Luiz Carlos de. Responsabilização, meritocracia e privatização: conseguiremos escapar ao neotecnicismo? III Seminário de Educação Brasileira promovido pelo CEDES no Simpósio PNE: Diretrizes para avaliação e regulação da Educação Nacional, p. 1-35, fev 2011. 


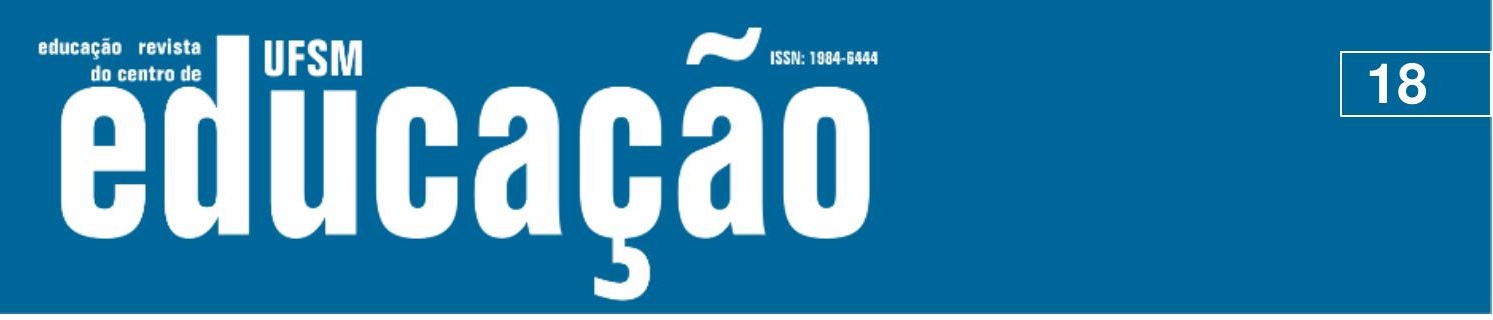

ISSN: 1984-6444 | http://dx.doi.org/10.5902/1984644434731

HERNANDES, Paulo. Romualdo. A Universidade Aberta do Brasil e a democratização do Ensino Superior público. Revista Ensaio, aval, pol.publ. Educ. Rio de Janeiro, 2017. Disponível em: http://dx.doi.org/10.1590/s0104-40362017002500777. Acesso em: 23/08/2017.

KUENZER, Acacia Zeneida. Trabalho e escola: a flexibilização do Ensino Médio no contexto do regime de acumulação flexível. Educação e Sociedade, Campinas, v. 38, n. 130, p. 331-354, 2017. Disponível em: http://dx/doi.org/101590/ES010173302027177723. Acesso em: 22/08/2017.

KUENZER, Acacia Zeneida. O Ensino Médio no contexto das políticas públicas de educação no Brasil. Revista Brasileira de Educação, Rio de Janeiro: Anped, n. 4, p. 77-95, 1997.

LIBÂNEO, José Carlos; OLIVEIRA, João Ferreira de; TOSCHI, Mirza Seabra. Educação escolar: políticas, estrutura e organização. 10. ed. São Paulo: Cortez, 2012.

MACEDO, Elizabeth. Base Nacional Comum Curricular: novas formas de sociabilidade produzindo sentidos para a educação básica. Revista e-Currículum, São Paulo, v. 1, n. 3p. 1530-1555,out/dez. 2014. Disponível em: http://revistas.pucsp.br/index.php/curriculum. Acesso em: 20/02/2018.

MARTINS, Lígia Martins. O desenvolvimento do psiquismo e a educação escolar: contribuições à luz da psicologia histórico-cultural e da pedagogia histórico-crítica. Campinas, SP: Autores Associados, 2013.

MOTTA, Vânia Cardoso da; FRIGOTTO, Gaudêncio. Por que a urgência da Reforma do Ensino Médio? Medida Provisória no 746/2016 (Lei no 13.415/2017). Educação e Sociedade, Campinas, v. 38, n. 139, p. 355-372, 2017. Disponível em: http://dx/doi.org/10.1590/ES0101-73302017176606. Acesso em: 27/02/2018.

PATTO, Maria Helena Souza. Escolas cheias, cadeias vazias. Nota sobre as raízes ideológicas do pensamento educacional brasileiro. Estudos Avançados, v. 21, n. 61, 2007. Disponível em: http://dx.doi.org/10.1590/S0103-40142007000300016.

PATTO, Maria Helena Souza. O ensino a distância e a falência da educação Educação e Pesquisa, v. 39, n. 2, p. 303-18, abr./jun. 2013. Disponível em: http://doi.org/10.1590/S1517-97022013000200002.

SAVIANI, Dermeval. Sistema Nacional de Educação articulado ao Plano Nacional de Educação. Revista Brasileira de Educação, Rio de Janeiro: Anped, Campinas: Autores Associados, v. 15, n. 44, 2010. Disponível em: http://www.scielo.br/pdf/rbedu/v15n44/v15n44a13.pdf. Acesso em: 27/04/2017. 


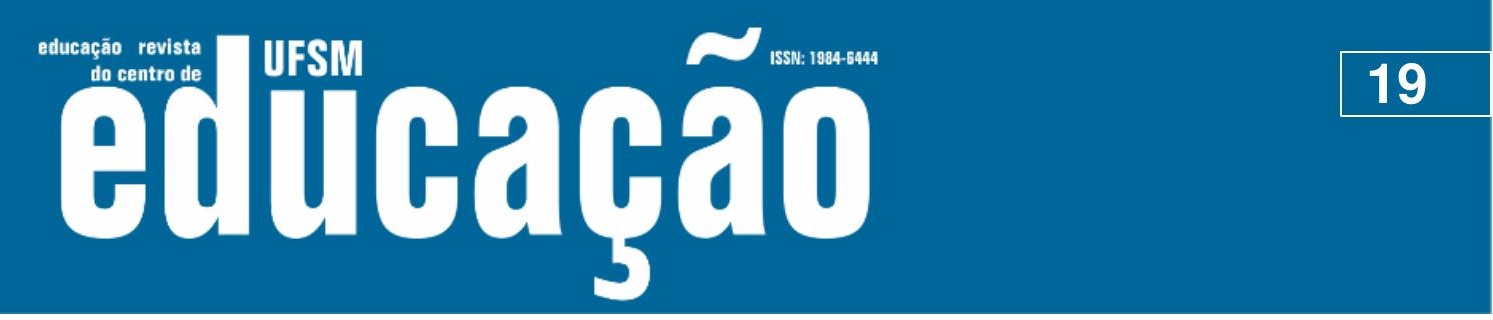

ISSN: 1984-6444 | http://dx.doi.org/10.5902/1984644434731

SAVIANI, Dermeval. Trabalho e educação: fundamentos ontológicos e históricos. Revista Brasileira de Educação, v. 12, n. 34, jan./abr. 2007. Disponível em http://www.scielo.br/pdf/rbedu/v12n34/a12v1234.pdf. Acesso em 25/04/2017.

SAVIANI, Dermeval. Pedagogia histórico-crítica: primeiras aproximações. 7. ed. Campinas, SP: Autores Associados, 2000.

SAVIANI, Dermeval. Escola e democracia: teorias da educação, curvatura da vara, onze teses sobre educação e política. 25. ed. São Paulo: Cortez, 1991.

SAVIANI, Dermeval. Da LDB (1996) ao novo PNE (2014-2024): por uma outra política educacional. 5. ed. Campinas, SP: Autores Associados, 2016.

SILVA, Karen Cristina Jensen Ruppel da; BOUTIN, Aldimara Catarina. Novo Ensino Médio e Educação Integral: contextos, conceitos e polêmicas sobre a reforma. Educação: Santa Maria, v. 43, n. 3, p. 521-534, jul./set. 2018 Disponível em http://dx.doi.org/10.5902/1984644430458. Acesso em 05/09/2018

TORRIGLIA, Patrícia Laura; ORTIGARA, Vidalcir. O campo de mediações. Primeiras aproximações para a pesquisa em políticas educacionais. In CUNHA, Célio; SOUZA, José Vieira de; SILVA, Maria. Abádia da. (orgs.). 0 método dialético na pesquisa em educação. Campinas, SP: Autores Associados; Brasília: Faculdade de Educação Universidade de Brasília, 2014.

\section{Correspondência}

Paulo Romualdo Hernandes - Universidade Federal de Alfenas - Rua Gabriel

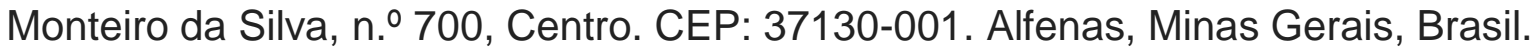

This work is licensed under a Creative Commons Attribution-NonCommercial 4.0 International (CC BY-NC 4.0)

\footnotetext{
' Não é intenção deste estudo debater se uma Base Nacional Comum Curricular para a educação básica será um avanço ou um retrocesso para a escola. Esse tema tem sido matéria de debates, posicionamentos, críticas e estudos de diversas entidades, instituições e especialistas da educação. A Associação Nacional de Pós-graduação e Pesquisa em Educação (ANPEd) tem se posicionado criticamente à metodologia como tem sido formulada a BNCC, com a participação somente de especialistas na área, sem incluir as comunidades educativas. Faz críticas, também, à homogeneização das matrizes curriculares, considerando os problemas que causará à autonomia das escolas e à formação de professores. Para obter mais informações, consultar: http://www.anped.org.br/news/nota-da-anped-sobre-entrega-da-terceira-versao-da-base-nacional-comumcurricular-bncc-ao (ANPED, 2017).
} 